\title{
$\mathrm{Ac} / \mathrm{Ds}$ 삽입 변이체를 이용한 벼 유전자 기능 연구
}

이강섭 · 박성한 · 윤도원 · 안병옥 · 김창국 · 한창덕 · 이기환 · 박동수 · 은무영 · 윤웅한

\section{Current status of Ac/Ds mediated gene tagging systems for study of rice functional genomics in Korea}

\author{
Gang-Seob Lee $\cdot$ Sung Han Park - Do-Won Yun - Byoung-Ohg Ahn · Chang-Kug Kim • Chang-Deok Han • \\ Gihwan Yi $\cdot$ Dong-Soo Park $\cdot$ Moo Young Eun $\cdot$ Ung-Han Yoon
}

Received: 18 April 2010 / Accepted: 29 April 2010

(c) Korean Society for Plant Biotechnology

\begin{abstract}
Rice is the staple food of more than $50 \%$ of the worlds population. Cultivated rice has the AA genome (diploid, $2 n=24$ ) and small genome size of only 430 megabase (haploid genome). As the sequencing of rice genome was completed by the International Rice Genome Sequencing Project (IRGSP), many researchers in the world have been working to explore the gene function on rice genome. Insertional mutagenesis has been a powerful strategy for assessing gene function. In maize, well characterized transposable elements have traditionally been used to clone genes for which only phenotypic information is available. In rice endogenous mobile elements such as MITE and Tos (Hirochika. 1997) have been used to generate gene-tagged popu-
\end{abstract}

The first two authors made equal contributions to this manuscript G.-S. Lee · S. H. Park · D.-W. Yun • B.-O. Ahn · C.-K. Kim • U.-H. Yoon $(\bowtie)$

국립농업과학원

(Genomics Division, National Academy of Agricultural Science, RDA, Suwon, Korea)

e-mail: uhyoon@korea.kr

C.-D. Han

경상대학교

(Plant Molecular Biology and Biotechnology Research Center, Gyeongsang National University, Jinju, Korea)

G. H. Yi · D.-S. Park

국립식량과학원

(Functional Crop Resource Development Division, Department of Functional Crop, National Institute of Crop Science, RDA, Suwon, Korea)

M. Y. Eun

경북대학교

(Kyungpook National University \& Gunwi Agriculture

Technology Center, Daegu, Korea) lations. To date T-DNA and maize transposable element systems has been utilized as main insertional mutagens in rice. A main drawback of a T-DNA scheme is that Agrobacteria-mediated transformation in rice requires extensive facilities, time, and labor. In contrast, the Ac/Ds system offers the advantage of generating new mutants by secondary transposition from a single tagged gene. Revertants can be utilized to correlate phenotype with genotype. To enhance the efficiency of gene detection, advanced gene-tagging systems (i.e. activation, gene or enhancer trap) have been employed for functional genomic studies in rice. Internationally, there have been many projects to develop large scales of insertionally mutagenized populations and databases of insertion sites has been established. Ultimate goals of these projects are to supply genetic materials and informations essential for functional analysis of rice genes and for breeding using agronomically important genes. In this report, we summarize the current status of Ac/Ds-mediated gene tagging systems that has been launched by collaborative works from 2001 in Korea.

서 론

벼는 세계적으로 가장 중요한 작물 중의 하나이며, 특 히 아시아권에서 소비가 가장 많이 되고 활용도가 높은 작물이다. 현재는 벼가 가지고 있는 여러 가지 영양성분 및 식미로 인하여 세계적으로 소비가 증가되는 추세에 있다. 또한 유전체의 크기가 작은 장점으로 인하여 단자 엽식물 최초로 염기서열 분석이 완료된 이후로 모델식물 로의 역할을 충실히 해 내고 있다 (Jun et al. 2002; Feng 
et al. 2002). 우수한 작물을 개발하기 위해 유용한 유전자 의 확보 및 분석이 필수적이며, 이러한 유전체 연구를 위 한 기초 자료로서 유전자 지도의 작성 및 이를 근거로 한 양적형질 분석이 실시되고 있는 실정이다.

금후 post-genome 시대의 연구방향은 유전자 기능분석 연구에 집중되고 있다. 특히 동·식물 게놈상의 전체 유전 자들에 대한 염기서열 분석을 통하여 동정된 유전자의 기능을 분석 할 수 있는 여러 방법과 기술이 개발되고 있다. 이들 유전자 기능분석 방법 중 삽입돌연변이를 통한 knockout 변이체 연구와 DNA chip을 이용한 유전자 발현 profile 분석연구는 생물학적 기능파악을 위하여 매우 공통적이 며 가장 강력한 도구중의 하나로 선택되고 있다. 애기장 대의 경우 gene knock-out과 microarray를 이용하여 T-DNA 에 의한 변이의 선발과 특정 조건에서 발현되는 유전자 들의 profile 연구가 수행되고 있으며, 전이인자 $\mathrm{dSpm}$ 을 이용한 변이집단 육성과 proteomics 및 microarray 관련 연 구가 수행되고 있다. 옥수수 게놈 분석연구는 전이인자 즉 $\mathrm{Mu}$ (Mutator), $\mathrm{Spm}$ (Suppressor/mutator), 그리고 Ac (Activator) family를 이용하여 transposon tagging을 통한 기능유 전체 연구에 중점을 두고 있다 (Greenblatt 1984; Dooner and Belachew 1989; Dooner et al. 1991). 벼의 경우 유전자의 기 능을 해명하기 위한 가장 효율적인 방법 중의 하나인 knockout된 변이체를 Tos17, T-DNA, Ac/Ds 삽입방법을 통 하여 작성하여 이들의 삽입염기서열을 분석하여 유전자 의 기능을 밝히는데 활용하고 있다 (Chin et al. 1999; Jeon et al. 2000; Kim et al. 2004). 본 리뷰는 벼의 삽입변이체 육성 및 그 분석에 대한 최근 동향을 소개하고자 한다.

\section{기능유전체 연구를 위한 벼 돌연변이 집단 양성}

식물의 유전체가 밝혀진 이후로 유전자의 정보를 근거 로 한 reverse genetics에 의한 유전자의 분석이 활기를 띠 게 되었는데(Parinov and Sundaresan, 2000) 애기장대의 경 우 데이터베이스에서 이러한 정보를 쉽게 활용할 수 있 게 되었다 (http://signal.salk.edu/Source/AtTOME_Data_Source. $\mathrm{html}$ ). 벼의 경우는 조직배양과정에서 retrotransposon이 유 전체상에서 다양하게 다른 염색체 또는 다른 부위로 전 이됨으로 새로운 변이를 만들 수 있다는 점을 이용하여 TOS-17 유래의 대규모 돌연변이 집단이 육성되었고 (Hirochika et al. 1996; Hirochika 1997), 아그로박테리움을 이 용하여 형질전환체를 육성하는 기술을 활용하여 T-DNA tagging 집단을 육성하게 되었는데 동진벼를 기반으로 하 여 100,000 계통의 삽입변이집단을 육성하였으며 (Jeon et al. 2000; Jeong et al 2002), Nipponbare를 기반으로 30,000여 계통을 육성하여 (Wu et al. 2003) 벼의 기능유전체 연구에 활용하고 있는 실정이다. 또한 옥수수의 transposon을 이 용하여 삽입변이집단을 양성하였는데 하나는 $\mathrm{Ac} / \mathrm{Ds}$ (Chin et al. 1999; Upadhyaya et al. 2002; Greco et al. 2003; Kolesnik et al. 2004)를 이용하였고 다른 하나는 $\mathrm{En} / \mathrm{Spm}-\mathrm{dSpm}$ 을 이용하여 삽입변이 집단을 육성하였으며 이들은 벼 염색체의 유전자부위에 $70 \%$ 가 삽입되었음이 보고되었다 (Greco et al. 2004; Kumar et al. 2005). Frameshift에 의한 Ac/ Ds 시스템은 새로운 돌연변이 육종체계에서 아주 중요 한 방법이며 이들은 하나의 single tagged 유전자로부터 2차 전이에 의한 새로운 유전자좌를 만드는데 아주 유용하게 활용될 수 있다. 대량의 Ds-tagging 집단은 전이를 유발하 고 전이인자가 선발됨으로서 작성 될 수 있으며 이러한 일련의 일들은 전이인자를 갖는 계통과 해리인자를 갖는 계통의 교배를 통한 방법과 이들 계통의 종자유래 캘러 스를 이용하여 형질전환을 시키는 방법으로 작성된다(Kim et al. 2004). 또한 Jiang (2007) 등은 옥수수의 Ac/Ds 전이인 자를 이용하여 20,000 계통의 벼 Ds 삽입변이체를 작성하 였다. 한국에서도 2007 년까지 조직배양을 이용하여 100,000 계통의 Ds 삽입변이체를 이미 육성하여 유전자 기능분 석에 활용하고 있다 (Park et al. 2007a). Knock-out 변이체 들이 가지고 있는 200,000 개 이상의 flanking sequence tags (FST)를 분석한 결과 약 $50 \%$ 가 단백질을 암호화 하는 것 으로 예측되었으며 이러한 결과는 Ds 삽입변이체가 유 용한 대규모의 집단이면서 육종에 활용할 수 있음을 시사 한다 (Krishinan et al. 2009). Krishinan (2009) 등은 206,668개 의 삽입 FST를 분석한 정보를 종합하였는데, 이중 180,639 개 의 FST가 벼의 게놈상에서 단일반복으로 일치하였으며 삽입변이체의 종류별로 다른 특이점을 보였는데 Tos17 이 엑손부분에 가장 높은 비율로 삽입되었음을 보고하였 다 (그림 1). 이들이 종합화한 정보중 Ds 삽입변이체에 관한것들만 모아 표 1 에 요약하였다.

한국에서도 작물유전체사업을 통하여 115,000 점의 Ds 삽입변이집단이 Ac/Ds gene trap system을 이용하여 육성 되었으며, 12,162 개의 Ds계통 중 467 개의 돌연변이가 분 류되어 분석되었다. FST 분석을 통하여 Ds의 삽입위치를 분석한 결과 전염색체에 걸쳐 Ds가 전이되었지만 3 번 염 색체에 Ds를 갖고 있는 starter line (Ds3, Ds43)으로 사용하 였기에 주로 3 번염색체로 전이되고 이웃한 1 번과 4 번 염

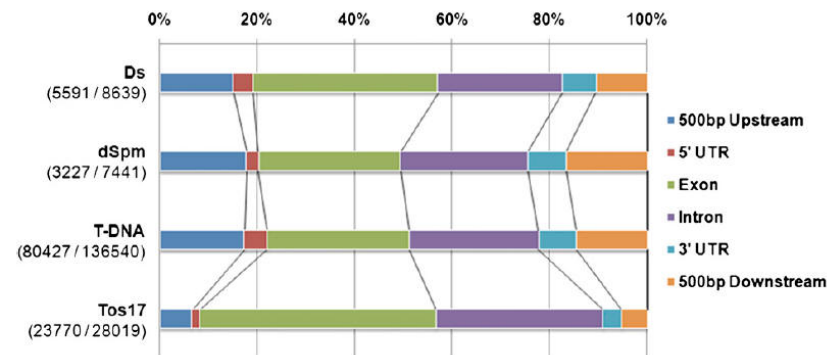

그림 1. Distribution of insertion positions within genic regions in rice (Krishinan et al. 2009) 
표 1 Mutant resources, contributors, and databases (Krishinan et al. 2009)

\begin{tabular}{|c|c|c|c|c|c|c|c|}
\hline Institution & Genotype & Mutagen & $\begin{array}{l}\text { Mutated } \\
\text { loci }\end{array}$ & FSTs & $\begin{array}{l}\text { FST Lines } \\
\text { Availability }\end{array}$ & Database website & Contacts \\
\hline $\begin{array}{l}\text { CSIRO Plant } \\
\text { Industry, AU }\end{array}$ & Nipponbare & $\begin{array}{l}A c D s \\
\mathrm{GT} / \mathrm{ET}\end{array}$ & 16,000 & 611 & $\begin{array}{c}\text { Approximately } \\
50 \% \text { lines no seed }\end{array}$ & $\begin{array}{l}\text { http://www.pi.csiro.a } \\
\text { u/fgrttpub }\end{array}$ & $\begin{array}{l}\text { N.M. Upadhyaya } \\
\text { upadhyaya@csiro.au }\end{array}$ \\
\hline EU-OSTID, EU & Nipponbare & $A c-D s$ ET & 25,000 & 1,380 & 1,300 & $\begin{array}{l}\text { http://orygenesdb.cira } \\
\text { d.fr }\end{array}$ & $\begin{array}{l}\text { E. Guiderdoni } \\
\text { guiderdoni@cirad.fr }\end{array}$ \\
\hline $\begin{array}{l}\text { GNU and } \\
\text { NAAS, KR }\end{array}$ & Dongjin Byeo & $A c-D s \mathrm{GT}$ & 30,000 & 4,820 & 4,820 & $\begin{array}{l}\text { KRDD } \\
\text { http://www.niab.go.k } \\
\text { r/RDS }\end{array}$ & $\begin{array}{l}\text { C.D. Han } \\
\text { cdhan@nongae.gsnu. } \\
\text { ac.kr }\end{array}$ \\
\hline $\begin{array}{c}\text { Temasek } \\
\text { Lifesciences, SG }\end{array}$ & Nipponbare & $A c-D s \mathrm{GT}$ & 20,000 & 2,000 & 2,000 & & $\begin{array}{l}\text { R. Srinivasan } \\
\text { sri@tll/org.sg }\end{array}$ \\
\hline UC Davis, US & Nipponbare & $\begin{array}{l}A c-D s \mathrm{GT} \\
\mathrm{Spm} / \mathrm{dSpm}\end{array}$ & 20,000 & $\begin{array}{r}\text { Ds } 4,735 \\
d S p m \\
9,469\end{array}$ & $\begin{array}{l}4,630 \\
9,036\end{array}$ & $\begin{array}{l}\text { http://www-plb.ucdav } \\
\text { is.edu/Labs/sundar }\end{array}$ & $\begin{array}{l}\text { V. Sundaresan } \\
\text { sundar@ucdavis.edu }\end{array}$ \\
\hline
\end{tabular}

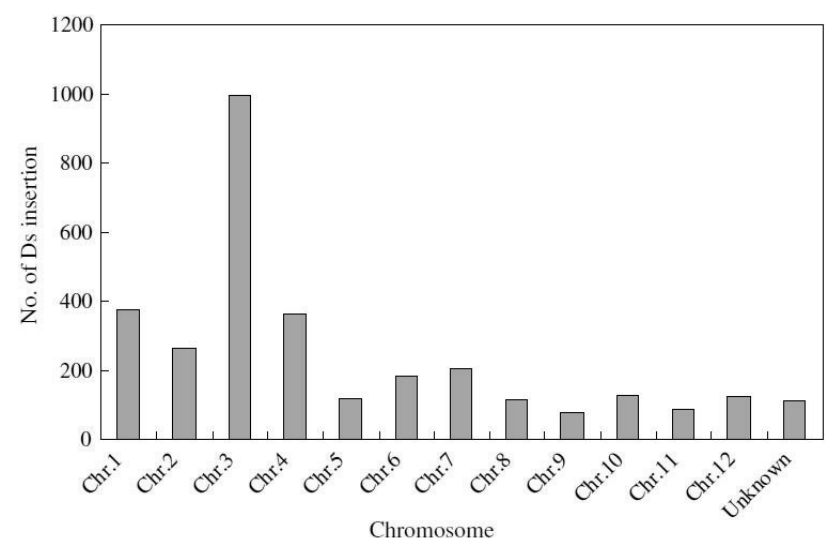

그림 2. The number of Ds insertions on each of the 12 chromosomes from the 3,123 Ds elements (Park et al. 2009)

색체에도 다른 염색체에 비해 많은 비율로 Ds가 전이되 었음을 확인 하였다 (그림 2). 양성된 Ds 돌연변이집단의 간장, 수장, 주당수수, 출수기 등 4가지 농업형질의 표현 형 변이를 분석한 결과 원품종인 동진벼에 비하여 각각 의 형질에서 크거나 적게 정규분포의 형태를 보였음을 보고하였으며, 또한 절간신장, 화기구조 및 종자크기 (그 림 3), 엽색 및 엽형태변이 (chlorophyll deficiency, drooping leaf, spotted leaf, brittle culm) 등 다양한 돌연변이체를 조 사하고 획득하였다 (Park et al. 2009). Ahn (2008) 등은 양 성된 Ds 집단의 서던 분석을 실시하여 벼 게놈상에서 $\mathrm{Ds}$ 는 평균 2 copy로 전이되었으며 조직부위별로 GUS 발현 을 조사한 결과 잎, 뿌리 및 화기관 등에서 약 $3.9 \%$ 가 발현 되었음을 확인하고 농업적으로 유용한 변이체 뿐만 아니 라 형태학적 변이를 보이는 twin seedling, dwarf, early heading, strip albino, liguless 등 변이체가 다수 발견됨으로 육종적
이용 및 유전자 기능해석을 위한 유용한 집단임을 시사 하였다.

\section{삽입돌연변이 집단을 이용한 유전자의 기능분석}

벼에서 삽입돌연변이체를 이용한 유전자 동정은 Tos17 유래 집단을 활용하여 처음으로 이루어졌는데, 전향유전 학적인 방법을 통하여는 수발아 유전자 (Agrawal et al. 2001) 그리고 후향유전학적인 방법을 통하여는 phytochrome A 유전자 (Takano et al. 2001)를 동정하였다. T-DNA를 이 용한 유전자의 기능분석으로는 전향유전학적인 방법을 통하여 엽록체 이상 변이와 관련이 있는 유전자 (Jung et al. 2003)를, 후향유전학적인 방법으로 PCR을 기반으로 하 여 MADS-box 유전자 선별을 통한 유전자 기능분석 (Lee et al. 2003)을 실시하였으며 또한 expression-based GT screen을 통한 방법으로 벼의 심백돌연변이 관련 유전자 의 기능을 분석하였다 (Kang et al. 2005).

Ds 삽입변이 집단을 이용한 벼의 유전자 동정 및 기능 분석은 벼의 이삭 및 화기구조에 결함이 있는 branched floretless $1(b f l)$ 를 삽입변이 집단에서 찾아 이들이 벼의 7번 염색체에 위치하며 이들이 이전에 보고된 frizzy panicle 유전자좌일 것이라는 것을 보고 (Zhu et al. 2003)하였고 또 벼의 dwarf Ds 삽입변이체를 찾아 이들의 $\mathrm{FST}$ 를 분석 한 결과 4 번 염색체에 위치한 $\mathrm{GA}$ 생합성 경로의 2차 단 계에 있는 ent-kaurene synthase (KS) 유전자임을 확인하고 $O s K S 1$ 은 발아와 뿌리 생장과는 관련이 없음을 보고하면 서 (Margis-Pinheiro et al. 2005) 시작되었다. 벼에서 불임의 표현형을 보이고 Ds가 삽입된 GUS 유전자에 의해 벼의 화분에 발현하는 변이체를 선발하여 이들의 FST 분석을 

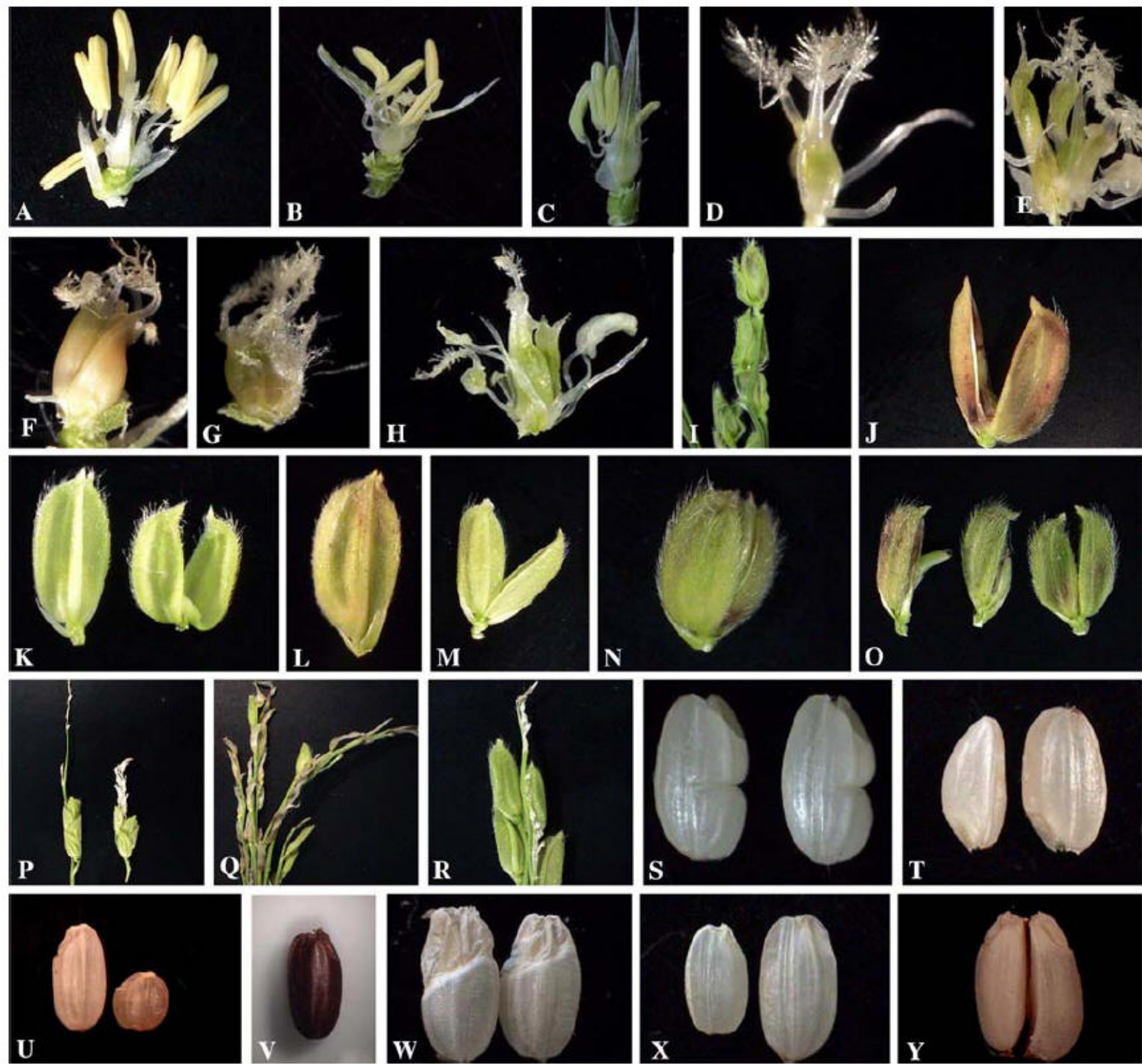

그림 3. Characterristics of different mutants from populations (Park et al. 2009)

통하여 Myosin XI 그룹 유전자에 Ds가 삽입된 것으로 확 인하였는데 이들은 단자엽식물에서 처음으로 발견된 myo$\sin$ 변이체였다. 이 변이체는 단일조건에서 웅성불임을 보이고 장일조건에서는 화분이 일부 활력을 띠는 것으로 보여 이 유전자는 화분발달과 관련이 있는 OSMYOXIB 유 전자임을 확인하였고, 이러한 변이체 연구를 통하여 식 물의 유전자 발현 기작에서 세포 표면 기작에 의한 화분 의 발달과 같은 새로운 발현양상을 알 수 있음을 보고하 였다 (Jiang et al. 2007).

식물의 잎 발달과 기관을 발생하는 유전자를 연구하 여, 그와 관련된 여러 유전자의 발현양상을 밝혀 식물의 수량과 성장에 관여하는 유전자들을 찾고자 Homeobox 유 전자를 이용하였는데, 이 유전자는 전사인자 역할의 기능
을 가지고 생장점에서의 줄기세포의 분화를 조절한다. 벼 의 Homeobox 유전자인 OSH6 유전자는 옥수수의 잎발달 에 관여하는 Lg3 (Liguless3)와 비슷한 유전자로 OSH6, Lg3 의 과발현 식물체는 둘 다 같은 잎 표현형인 'blade to sheath transformation'을 보인다. 옥수수 전이인자를 이용한 벼의 $\mathrm{Ac} / \mathrm{Ds}$ 전이인자 삽입변이집단에서 선발된 새로운 형질의 OSH6-Ds 형질은 3 번째 위치의 exon에 Ds가 삽입되어 절 단된 형태의 mRNA가 형성되고, 정상적인 OSH6 유전자의 발현양상인 줄기와 꽃의 생장점에서의 발현 뿐만 아니 라, 특이적으로 잎에서도 발현된다. 새로운 형질의 OSH6Ds는 꽃대의 절단 부위의 포엽이 비정상적으로 발달된 형태의 표현형을 보이는데, 정상적인 식물체는 포엽이 이미 퇴화된 기관으로 알려져 있다. 이러한 표현형적 변 


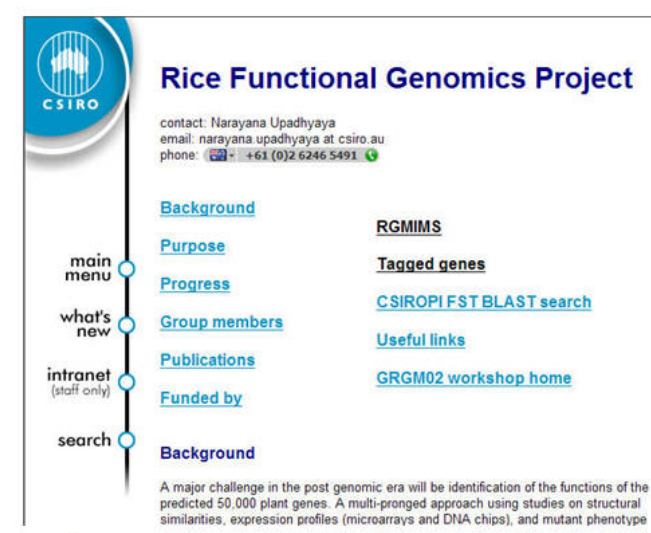

http://www.pi.csiro.au/fgrttpub

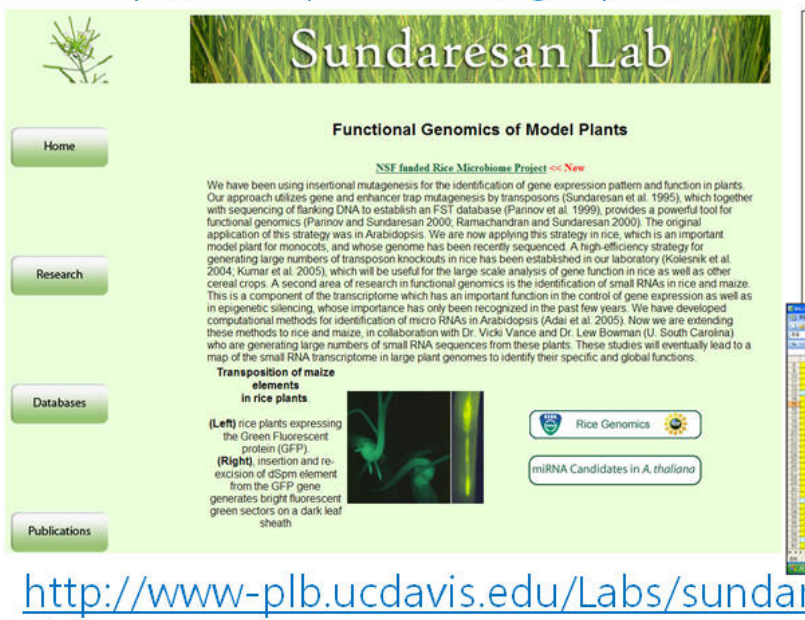

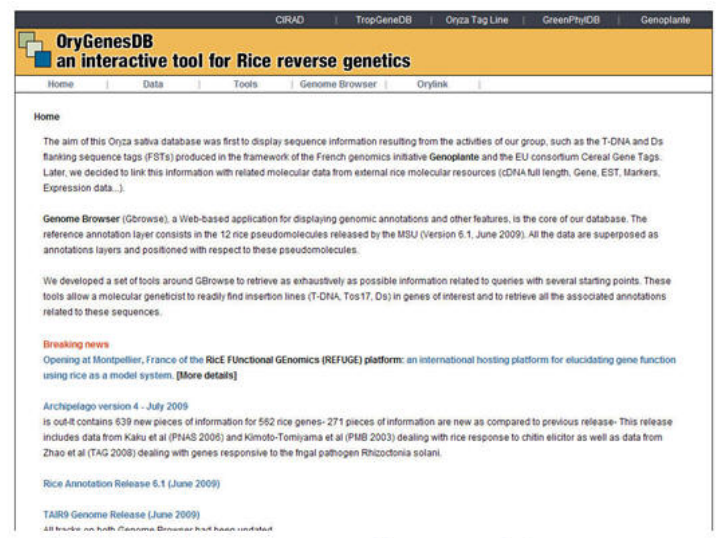

http://orygenesdb.cirad,fr/

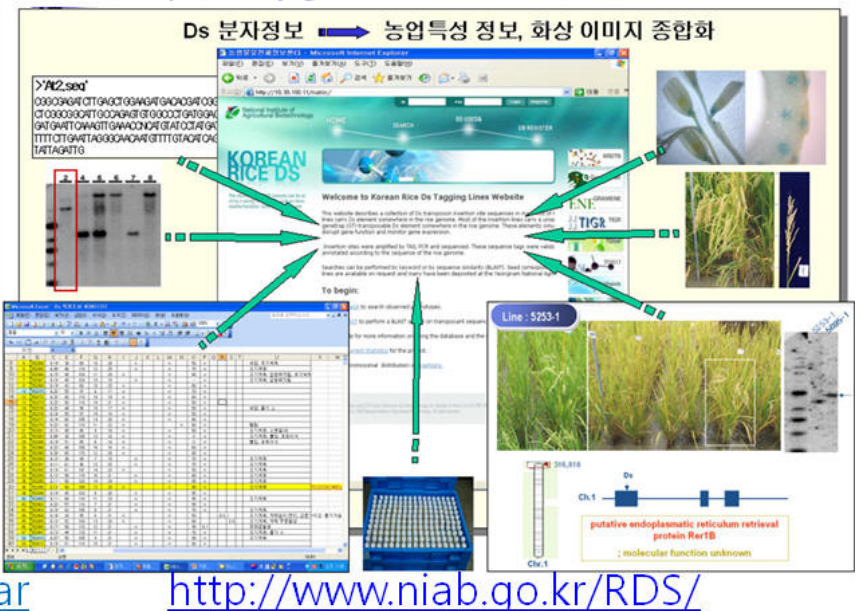

그림 4. Public Database related to Ds insertional mutants

화가 새로 형성된 유전형질에 의해 형성되는지를 확인하 기 위하여 절단된 OSH6-Ds 전사체를 과발현시킨 형질전 환체를 구축하고 그 표현형을 관찰한 결과 OSH6-Ds 변 이체와 같은 꽃대의 표현형을 보임을 알 수 있는데 전이 인자의 삽입에 따라 새로운 유전형질을 형성하고, 특이 적인 발현양상을 통하여 정상적인 유전자 $(\mathrm{OSH} 6)$ 와의 상 호적인 작용을 통하여 새로운 기능을 나타냄을 확인하였 다 (Park et al. 2007b).

벼의 뿌리털 발달에 관여하는 유전자는 영양분의 흡수 나 식물의 성장에 많은 영향을 준다. 이는 벼의 수확량에 직접적인 영향을 주는 요소이므로 뿌리털의 발달기작을 밝히기 위하여 뿌리털의 성장에 직접 관여하는 유전자인 OsCSLD1을 Ac/Ds를 이용한 벼 전이집단에서 동정하여 분석하였다. Ds의 삽입으로 knock-out된 유전자는 뿌리털 의 발달을 현저히 저해하여 식물의 발달을 저해하는데 이를 증명하기 위하여 과발현식물체를 유도하고 재분화 를 통하여 revertant 식물체를 만들어 뿌리털이 형성되는 것을 확인하여 뿌리털의 발달기작을 보고하였다(Kim et al. 2007).
기능유전체 분석용으로 육성된 돌연변이 집단들은 조 직배양을 거치면서 벼 게놈내에 존재하는 수많은 transposon이 임의로 다른 염색체에 전이되면서 원치 않는 변 이를 재생산 하게 되는데 이러한 기대하지 않은 변이는 형태적인 표현형변이와의 연관 비율을 낮추어 유전자 기 능연구에 장애가 되고 있다. 상대적으로 Ds 삽입변이집 단은 전이인자의 원치 않는 돌연변이 비율이 낮아 유전 분석 및 유전자의 복수 돌연변이의 활용이 가능하여 전 향유전적인 방법을 활용하는 환경 및 병해에 대한 선별 이 가능하고 모본의 표현형을 회복하는 방법을 통해 유 전자-표현형간의 관계를 밝히는데 유용한 재료로 사용된 다 (Zhu et al. 2007). 또한 분자육종법을 통한 생산량의 증 가를 위한 연구의 한 방법으로 화분의 발달 시기에 관여 하는 유전자들의 연구를 통하여 화기 형성시기의 단계별 기작을 구명하고자 Id1 (Indeterminate 1)의 벼 유사 유전자 인 OsId1을 동정하여 효모를 이용한 유전자의 발현기작 연구와 RNAi기법을 통하여 유전자의 기능을 연구하였 다. OsId1 유전자의 발현이 억제되면 장일과 단일에 상관 없이 화기의 발달이 억제되었는데, 이것은 화기의 발달 
에 관여하는 Early heading date 1과 Hda3a, RFT1 등의 유 전자 발현을 조절하여 화기 발달을 억제함을 알 수 있었 다. 또한 이러한 유전자들의 조절작용은 기존에 밝혀진 OsGL, OsMADS 유전자들의 조절기작과는 별개의 새로 운 화기발달 조절기작임을 밝혀 OsId1에 의한 Ehd1의 발 현 증가는 화기의 발달을 촉진함을 구명하였다 (Park et al. 2008). 장일과 단일 조건에 상관없이 화기를 조절하는 유전자의 동정은 고전육종에서의 작물의 개량과 마찬가 지로 분자육종을 위한 좋은 재료이다. 일장에 대하여 덜 영향을 받고 유전자의 발현만으로도 화기를 조절한다면 작물 유래 고기능성 단백질을 대량 육성 할 수 있는 분자 육종 모본의 적합한 재료로 이용할 수 있다. 조기출수 변 이체와 수량성이 확보된 삽입변이체를 이용한 육종모본 의 사용시 현재 기능성 함유 식물체 개발의 제한성을 해 결하고 고품질 식량자원의 안정적인 공급과 우수품종을 확보할 수 있을 것이다.

\section{돌연변이집단 데이터베이스}

Ds 삽입변이체의 FST정보를 이용하여 유전자를 분석 하고 이들 유전자의 기능 확인을 쉽게하기 위하여 여러 개의 데이터베이스가 존재한다. 이들 데이터베이스는 기 본적으로 FST 정보를 제공하고 있으며 표현형 정보도 제 공하여 향후 phenome연구의 기반을 제공하려 한다 (표 1). 호주의 CSIRO에서 운영하는 Rice Functional Genomics Project (RFGP)에서는 tagged gene 정보를 제공하고 있으며 (http://www.pi.csiro.au/fgrttpub), EU의 EU-OSTID에서 운영 하는 OryGenesDB는 Ds 삽입변이체 뿐만 아니라 T-DNA 의 FST 정보를 제공하고 있으며 (http://orygenesdb.cirad,fr/), UC Davis의 Sudaresan 그룹도 웹페이지에 벼 및 애기장대 의 기능유전체에 대하여 대략적인 소개 및 링크를 통하 여 성과 및 정보를 공유하고 있다 (http://www-plb.ucdavis. $\mathrm{edu} / \mathrm{Labs} / \mathrm{sundar}$ ). 한국에서는 115,000 개의 양성된 Ds 삽입 변이체의 정보를 분석하여 이들의 특성을 제공하고 있는 데 (그림 3), 여기에는 분석된 FST정보, 표현형 정보, 서던 분석 자료, GUS 정보 등이 포함된다 (KRDD, http://www. niab.go.kr/RDS/).

\section{향후 전망 및 결론}

벼 유전체 구조가 완료된 후 post-genome시대의 연구 방향은 유전자 기능분석 연구에 집중되고 있다. 벼에서 발현하는 유전자는 다른 곡류에서도 발현하는 것으로 알 려져 다양한 생명공학 기술을 이용한 유용유전자를 분리 하는데 유용하며 벼 유전자의 효율적인 대량기능분석 방 법으로는 벼의 유전자가 임의로 파괴된 삽입돌연변이 계
통을 대량으로 육성하고 파괴된 유전자부위의 염기서열 정보와 삽입돌연변이 계통의 형태 및 생리대사 특성을 비교하여 유전자의 기능을 해석하는 것이다. 벼의 유전 자의 기능해석을 위하여 전 세계적으로 다양한 방법을 이용하여 삽입변이집단을 양성하여 전향유전학적인 방 법과 후향유전학적인 방법을 통하여 연구가 수행되고 있 다. 국내에서도 Ds 전이인자를 이용하여 115,000 계통의 벼 삽입변이집단을 육성하고 이들의 FST 분석하였다. 또 한 표현형변이를 나타내는 계통을 찾아내고 이들의 특성 을 분석하여 데이터베이스화하고 있다. 방대한 삽입변이 집단을 효율적으로 활용할 방법이 앞으로 기획되어야 하 며 삽입변이집단을 이용하여 환경내성 및 병저항성 스크 리닝을 통한 유전자의 특성을 파악하고 동정하여 이를 활용하는 방법을 개발해야 할 것이다. 벼 유전자는 유전 체 정보해석을 통해 평균적으로 4 만 여개에 이르는데 반 해 우리가 육안으로 관찰할 수 있는 표현형변이는 한계 가 있으며 또한 표현형 변이를 보인다 해도 그것이 환경 적인 변이인지 구분하기 위해 후대 분석이 필요하다. 또 한 연속적인 변이를 보이는 생리적인 형질, 대사와 관련 된 변이, 지하부의 변이 등은 조사자체가 상당히 어렵다.

최근 기능유전체 연구의 효율을 높이기 위하여 변이체 에 대한 총체적인 해석과 함께 변이체의 표현형 변이와 삽입염기서열 분석의 연관성을 데이터 베이스화하는 이 른바 phenome 데이터베이스로 가는 추세이다. 이러한 phenome 분석에 삽입변이집단의 데이터베이스가 활용될 것으로 기대된다.

\section{사 사}

이 연구는 농촌진흥청 어젠다 2-7-11 "벼 변이집단 및 생물정보를 이용한 유용농업형질 유전자 탐색" 과제와 작물유전체사업 CG3310 "형질전환 작물의 유전분석 및 실용화” 과제지원에 의해 수행되었다.

\section{인용문헌}

Agrawal GK, Yamazaki M, Kobayashi M, Hirochika R, Miyao A, Hirochika H (2001) Screening of the rice viviporous mutants generated by endogenenous retrotransposon Tos 17 insertion. Tagging of a zeaxanthin epoxidase gene and a novel OSTATC gene. Plant Physiol 125:1248-1257

Ahn BO, Kang KH, Eun MY, Jeon YH, Yun DW, Ji HS, Park SH, Nam MH, Suh SC, Lee MC (2008) Trait variation and molecular characterization of Ds insertional rice lines. Korean J Breed Sci 40(1):39-47

Chin HG, Choe MS, Lee SH, Park SH, Koo JC, Kim NY, Lee JJ, Oh BG, Yi GH, Kim SC, et al. (1999) Molecular analysis of rice 
plant harboring an Ac/Ds transposable element-mediated gene trapping system. Plant J. 19:615-623

Dooner HK and Belachew A (1989) Transpositional pattern of the maize element Ac from the bz-m2(Ac) allele. Genetics 122: 447-457

Dooner HK, Keller J, Harper E, Ralston E (1991) Variable patterns of transposition of maize element Activator in tobacco. Plant Cell 3:473-482

Feng Q, Zhang Y, Hao P, Wang S, et al. (2002) Sequence and analysis of rice chromosome 4. Nature 420:316-320

Greco R, Ouwerkerk PB, De Kam RJ, Sallaud C, Favalli C, Colombo L, Guiderdoni E, Meijer AH, Hoge JH, Pereira A (2003) Transpositional behavior of an Ac/Ds system for reverse genetics in rice. Theor Appl Genet 108:10-24

Greco R, Ouwerkerk PB, Taal AJ, Sallaud C, Guiderdoni E, Meijer AH, Hoge JH, Pereira A (2004) Transcription and somatic transposition of the maize $\mathrm{En} / \mathrm{Spm}$ transposon system in rice. Mol Genet Genomics 270:514-523

Greenblatt IM (1984) A chromosome replication pattern deduced from pericarp phenotypes resulting from movements of the transposable element, modulator, in maize. Genetics 108: 471-485

Hirochika H, Sugimoto K, Otski Y, Tsugawa H, Kanda M (1996) Retro- transposones of rice involved in mutations induced by tissue culture. Proc. Natl. Acad. Sci. USA 93:7783-7788

Hirochika H (1997) Retrotransposons of rice : their regulation and use for genome analysis. Plant Mol. Biol. 35:231-240

Jeon JS, Lee S, Jung KH, Jeong DH, Lee J, Kim C, Jang S, Yang K, Nam J, An K, Han MJ, Sung RJ, Choi HS, Yu JH, Choi JH, Cho SY, Cha SS, Kim SI, An G (2000) T-DNA insertional mutagenesis for functional genomics in rice, Plant $\mathrm{J} 22$ : 561-570

Jeong DH, An S, Kang HG, Moon S, Han JJ, Park S, Lee HS, An $\mathrm{K}$, An G (2002) T-DNA insertional mutagenesis for activation tagging in rice, Plant Physiol, 130:1636-1644

Jiang SY, Bachman D, La H, Ma Z, Venkatesh PN, Ramamoorthy $\mathrm{R}$, Ramachandran S (2007) Ds insertion mutagenesis as an efficient tool to produce diverse variation for rice breeding. Plant Mol Biol 65:385-402

Jiang SY, Cai M, Ramachandran S (2007) ORYZA SATIVA MYOSIN XI B controls pollen development by photoperiodsensitive protein localizations. 304:579-592

Jun Y, Songnian H, Jun W, Gane Ka-Shu W et al. (2002) A draft sequence of the rice genome(Oryza sativa L. ssp. indica). Science 296:79-91

Jung KH, Hur J, Ryu CH, Choi Y, Chung YY, Miyao A, Hirochika H, An G (2003) Characterization of a rice chlorophyll-deficient mutant using the T-DNA gene-trap system. Plant Cell Physiol 44:463-472

Kang HG, Park S, Matsoka M, An G (2005) White-core endosperm floury endosperm-4 in rice is generated by knockout mutation in the C-type pyruvate orthophosphate dikinase gene (OsPPDKB). Plant J 42:901-911

Kim CM, Park SH, Je BI, Park SH, Park SJ, Piao HL, Eun MY, Dolan L, Han CD (2007) OsCSLD1, a Cellulose Synthase-
Like D1 gene, is required for root hair morphogenesis in rice. Plant Physiol 143:1220-1230

Kim CM, Piao HL, Park SJ, Chon NS, Je BI, Sun B, Park SH, et al. (2004) Rapid, large-scale generation of Ds transposant lines and analysis of the Ds insertion sites in rice. Plant J. 39(2): 252-263

Kolensik T, Szeverenyi I, Bachman D, Kumar CS, Jiang S, Ramamoorthy R, Cai M, M ZG, Sundaresan V, Ramachandran S (2004) Establishing an efficient Ac/Ds tagging system in rice: large-scale analysis of Ds flanking sequences. Plant J. 37:301-314

Krishinan A, Guiderdoni E, An G, Hsing YC, Han CD, Lee MC, Yu SM, Upadhyaya N, Ramachandran S, Zhang Q, Sundaresan V, Hirochika H, Leung H, Pereira A (2009) Mutant resources in rice for functional genomics of the rice grasses. Plant Physiol 149:165-170

Kumar CS, Wing RA, Sundaresan V (2005) Efficient insertional mutagenesis in rice using the maze En/Spm elements. Plant J 44:879-892

Lee S, Kim J, Son JS, Nam J, Jeong DH, Lee K, Jang S, Yoo J, Lee J, Lee DY, et al. (2003) Systemic reverse genetic screening of T-DNA tagged genes in rice for functional genomic analysis: MADS-box genes as a test case. Plant Cell Physiol 44: 14031411

Margis-Pinheiro M, Zhou XR, Zhu QH, Dennis ES, Upadhyaya $\mathrm{NM}$ (2005) Isolation and characterization of a Ds-tagged rice (Oryza sativa L.) GA-responsive dwarf mutant detective in an early step of the gibberellin biosynthesis pathway. Plant Cell Report 23:819-833

Parinov S, Sundaresan V (2000) Functional genomics in Arabidopsis: large-scale insertional mutagenesis complements the genome sequencing project. Curr Opin Biotechnol 11:157-161

Park DS, Park SK, Han SI, Wang HJ, Jun NS, Manigbas NL, Woo YM, Ahn BO, Yun DW, Yoon UH, Kim YH, Lee MC, Kim DH, Nam MH, Han CD, Kang HW, Yi GH (2009) Genetic variation through Dissociation (Ds) insertional mutagenesis system for rice in Korea: progress and current status. Mol Breeding 24:1-15

Park SH, Jun NS, Kim CM, Oh TY, Huang J, Xuan YH, Park SJ, Je BI, Piao, HL, Park SH, et al. (2007a) Analysis of gene-trap Ds rice population in Korea. Plant Mol Biol 65:373-384

Park SH, Kim CM, Je BI, Park SH, Park SJ, Piao HL, Xuan YH, Choe MS, Satoh K, Kikuchi S, Lee KH, Cha YS, Ahn BO, Ji HS, Yun DW, Lee MC, Suh SC, Eun MY, Han CD (2007b) A Ds-insertion mutant of OSH6 (Oryza sativa Homeobox 6) exhibits outgrowth of vestigial leaf-like structures, bracts, in rice. Planta 227:1-12

Park SJ, Kim SL, Lee SY, Je BI, Piao HL, Park SH, Kim CM, Ryu CH, Park SH, Xuan YH, Colasanti J, An G, Han CD (2008) Rice Indeterminate 1 (Osld1) is necessary for the expression of Ehd1 (Early heading date 1) regardless of photoperiod. The Plant Journal 56:1018-1029

Takano M, Kanegae H, Shinomura T, Miyao A, Hirochika H, Furuya M (2001) Isolation and characterization of rice phytochrome A mutants. Plant Cell 13:521-534 
Upadhyaya NM, Zhou XR, Ramm K, Zhu QH, Wu L, Eamens A, Sivakumar R, Kato T, Yun DW, Kumar S, et al. (2002) An $\mathrm{iAc/Ds}$ gene and enhancer trapping system for insertional mutagenesis in rice. Funct Plant Biol 29:547-559

Wu C, Li X, Yuan W, Chen G, Kilian A, Li J, Xu C, Li X, Zhou DX, Wang S, Zhang Q (2003) Development of enhancer trap lines for functional analysis of the rice genome. Plant J. 35:418-4270

Zhu QH, Eun MY, Han CD, Kumar CS, Pereira A, Ramachandran S, Sundaresan V, Eamens AL, Upadhyaya NM, Wu R (2007)
Transposon insertional mutants: a resource for rice functional Genomics. In NM Upadhyaya. ed, Rice Functional Genomics Challenges, Progress and Prospects. Springer, New York, pp. 223-271

Zhu QH, Hoque MS, Dennis ES, Upadhyaya NM (2003) Ds tagging of BRANCHED FLORETLESS 1 (BFL1) that mediates the transition from spikelet to floret meristem in rice (Oryza sativa L.) BMC Plant Biology 3:6 